\section{Cogitação e prática do aborto entre jovens em contexto de interdição legal: o avesso da gravidez na adolescência}

\author{
Considering and submitting to abortion among \\ young people in the context of legal prohibition: \\ the hidden side of teenage pregnancy
}

Simone Ouvinha Peres 1 Maria Luiza Heilborn 2

\footnotetext{
1 Instituto de Psicologia Universidade Federal do Rio de Janeiro, Rio de Janeiro, Brasil. 2 Instituto de Medicina Social, Universidade do Estado do Rio de Janeiro, Rio de Janeiro, Brasil.

Correspondência S. O. Peres

Instituto de Psicologia Universidade Federal do Rio de Janeiro. Av. Pasteur 250, fundos, Rio de Janeiro, $R J$ 22290-240, Brasil. ouvinhaperes@uol.com.br simoneperes@psycho.ufrj.br
}

\begin{abstract}
This article aims to unveil the notion of abortion as an element in young people's thoughts on teenage pregnancy. The study analyzes data from semi-structured interviews with 123 young men and women 18-24 years of age in Porto Alegre, Rio de Janeiro, and Salvador, Brazil, belonging to different social strata. Based on information concerning their affective, sexual, and reproductive circumstances, an abortion typology was established with a gradient ranging from considering the act to the attempt to materialize it, actually submitting to abortion, and even ruling out the possibility of interrupting the pregnancy. According to the data, 73\% of interviewees had considered the possibility of an abortion, demonstrating an important presence of this notion as a recourse vis-à-vis an unpredicted pregnancy, even in the Brazilian context where abortion is illegal. Among the 86 young people who had experienced a pregnancy, 27 reported having resorted to abortion (20 males and seven females). The results indicate gender differences and contribute to an understanding of teenage pregnancy by examining induced abortion, a hidden dimension in the public and scientific debate on this issue.
\end{abstract}

Induced Abortion; Pregnancy in Adolescence; Sexuality

\section{Introdução}

Este artigo examina o aborto, circunscrevendoo à problemática da gravidez na adolescência. Nas últimas décadas, a gravidez nessa etapa da vida vem sendo tratada no país como um problema social, levando a um conjunto de ações de políticas públicas voltadas para seu controle $1,2,3$. Na literatura especializada sobre a temática convencionou-se chamar de crescimento da gravidez na adolescência o fenômeno do aumento da sua ocorrência entre os 10 e 19 anos, em contraste com o declínio observado em relação à fecundidade do total de mulheres em idade fértil no Brasil 4,5,6. A este dado é preciso acrescentar o aumento na proporção de partos realizados entre as adolescentes.

Diversos autores associam a gravidez na adolescência a uma gama heterogênea de fatores: dos eventuais riscos de saúde aos prejuízos sociais para as jovens que engravidam precocemente 7,8,9,10,11,12,13,14,15. A proliferação discursiva em torno do fenômeno resulta da expectativa social hegemônica em relação aos adolescentes, preconiza uma escolarização prolongada, um controle contraceptivo adequado e privilegia a constituição de uma família. Espera-se que os jovens cumpram trajetórias ideais e obedeçam a etapas pré-determinadas, como a conclusão dos estudos e a inserção no trabalho - visão que corrobora o evento da gravidez como inoportuno e fruto de impru- 
dência. Neste sentido são ressaltados os riscos da associação da gestação com maternidade celibatária e o contexto de pobreza material 13 . Na maioria dos trabalhos em que o tema é analisado, é dada maior ênfase à maternidade e suas conseqüências. A gravidez interrompida por abortamento é parcamente analisada 16,17,18.

O aborto é um relevante problema de saúde pública no Brasil, na medida em que é praticado amplamente pelas mulheres em contexto clandestino, com meios inseguros e por profissionais despreparados 13,19,20. Nas estatísticas de mortalidade, os dados relacionados à hospitalização indicam o aborto como uma das principais causas de morte no país 21 o que é ainda mais contundente quando se verifica que a prática da interrupção da gravidez espelha as desigualdades sociais brasileiras 13,17,22. As jovens sujeitas à maior exclusão social são justamente as que recorrem mais freqüentemente aos hospitais públicos em busca de procedimentos, como curetagem pós-aborto, e declaram gravidezes não planejadas 23,24. Estudos epidemiológicos voltam-se majoritariamente para uma descrição do perfil das mulheres, das variáveis sócio-demográficas e dos métodos utilizados 8,17,19,20: eles não se detêm sobre as representações construídas pelas mulheres que optaram por essa intervenção, o que impede o conhecimento acerca das práticas do aborto. Pesquisas com população geral permitem, por seu lado, descortinar o universo de casos que não chega aos hospitais 18,25,26.

As pesquisas sobre a gravidez na adolescência - definida pela Organização Mundial da Saúde (OMS) como a que ocorre entre os dez e vinte anos incompletos 27 - se limitam a tratar dos condicionantes da gravidez, sem levar em conta a influência da ilegalidade nas conseqüências da tomada de decisão dos jovens relativa à interrupção ou prosseguimento da gestação. Os estudos não tratam dos problemas específicos enfrentados pelos adolescentes face à escolha do aborto: as formas de acesso a recursos materiais, a premência de tempo para a realização da intervenção em contexto ilegal, a minoridade civil, a consulta a um médico, a realização de exames, até efetivamente a concretização do aborto em clínicas clandestinas ou pelo uso de medicamentos sem controle adequado. Com o enquadramento jurídico da prática do aborto como ilegal - as leis brasileiras não punem o aborto apenas em duas circunstâncias: resultante de estupro ou situações que representem risco de vida para a gestante 28 - ocorrem restrições à análise dos contextos empíricos no quais o aborto é realizado, servindo de obstáculo à investigação dos signifi- cados e conseqüências da gravidez na adolescência.

A ausência de debates sobre a especificidade da interrupção da gravidez favorece uma visão reducionista sobre o significado desse evento no início da trajetória reprodutiva, na medida em que não é levado em conta o fato de que a decisão sobre a continuidade de uma gravidez abriga, ainda que de forma não revelada, a eventual possibilidade dos ônus e riscos da opção pelo aborto. A influência e a autoridade dos pais sobre os jovens também não são examinadas nos trabalhos. Deve-se também considerar que algumas jovens omitem dos familiares a informação da gravidez. Por fim, não são conhecidas as circunstâncias nas quais o casal adolescente realiza uma escolha sem consultar a família, busca recursos para o aborto e o concretiza, o que implica o conhecimento dos modos de negociação desenvolvidos entre os dois jovens. Assim, a impossibilidade legal do aborto deve integrar a multiplicidade de fatores envolvidos em qualquer análise sobre a reprodução no início da vida sexual e reprodutiva. Entre jovens, ainda em fase de aprendizado do exercício da sexualidade com o parceiro e do contexto relacional ali implicado, a idéia do aborto está presente desde o momento da descoberta da situação. Trata-se das circunstâncias da notícia e da revelação da gravidez à família, ao parceiro ou aos pares, até a deliberação de realizá-lo com os recursos disponíveis, uma vez que esse procedimento não é acessível a qualquer adolescente que o deseje.

Este estudo tem por objetivo demonstrar como o aborto pode integrar as reflexões sobre uma gravidez não prevista na adolescência. Para tal, enfoca as narrativas acerca da primeira gestação, tenha ela sido levada a termo ou não. Cabe ainda destacar que freqüentemente estudos sobre reprodução ou aborto excluem depoimentos dos homens $8,12,29$. Sob nosso ponto de vista, a diferença de gênero é um fator relevante na condução do processo decisório. $\mathrm{O}$ desfecho tanto pode incluir a escolha pela maternidade ou paternidade, como também pelo aborto compartilhado ou solitário. Assim, este trabalho busca tornar o aborto visível sob distintos prismas: como uma idéia possível diante da gravidez, e não apenas a partir de sua prática efetiva e/ou tentativas, o que significa conferir à interrupção da gestação um lugar legítimo entre os eventos relativos à reprodução 23,30. 


\section{Sobre as estratégias metodológicas e procedimentos de pesquisa}

\section{Universo de estudo}

Este artigo examina os dados resultantes da etapa qualitativa da Pesquisa GRAVAD (Gravidez na Adolescência: Estudo Multicêntrico sobre Jovens, Sexualidade e Reprodução no Brasil), que investiga os comportamentos sexuais e reprodutivos de jovens residentes em Porto Alegre, Rio de Janeiro e Salvador, Brasil. Foram realizadas 123 entrevistas semi-estruturadas com jovens de 18 a 24 anos de ambos os sexos, pertencentes a distintos estratos sociais, que experienciaram (ou não) uma gravidez antes dos vinte anos, a partir de um critério de cotas pré-definido 31,32 . Em relação à primeira gestação, investigou-se o contexto no qual ela ocorreu (idade, parceria e apoios). Nas quarenta entrevistas estipuladas por cidade, decidiu-se que seriam vinte de homens e vinte de mulheres. A influência das relações de gênero nas interações entre os parceiros e nos comportamentos reprodutivos leva a incluir os homens na população de jovens a ser investigada. Do total dos quarentas informantes previstos para cada cidade, 13 pertencem a camadas populares e sete a camadas médias da população. Em relação ao segmento social, foi decidido que, no caso de pertencimento a camadas populares, oito jovens teriam experiência reprodutiva e cinco não a teriam, enquanto para os de camadas médias, quatro teriam e três não teriam essa condição. O recorte etário da população entrevistada não seguiu a definição da OMS para adolescência 27 , tendo em vista que o pertencimento a idades ligeiramente superiores permite descrever os desdobramentos das trajetórias sexuais, conjugais e reprodutivas após a adolescência. A escolha da idade dos jovens considerou também maioridade civil, autonomia e liberdade para tomar a decisão de participar da pesquisa, sem a necessidade de conhecimento e autorização dos pais. Os informantes foram contatados por redes de sociabilidade diversificadas, abrangendo o maior número possível de locais de interação de jovens. A técnica de bola de neve, através da qual cada jovem podia indicar outros para serem entrevistados, também foi utilizada.

O universo de 123 jovens entrevistados em 2000 é assim constituído por 81 informantes do segmento popular e por 42 do segmento médio. Como critério para a estratificação por classe, foram utilizados os dados do Instituto Brasileiro de Geografia e Estatística (IBGE), a partir da Pesquisa Nacional por Amostras de
Domicílios (PNAD) de 1997, que apresenta uma distribuição da renda familiar per capita por decis 32 . Foram levados em conta outros referenciais para a classificação da situação de classe, observados no momento da entrevista, tais como propriedade de imóvel e outros bens duráveis, condição de moradia, número de eletrodomésticos, situação sócio-econômica do bairro ou vizinhança (se é favela ou não; se há luz, saneamento básico, água encanada) e oferta de bens culturais e lazer. A descrição detalhada das condições de moradia, de sobrevivência e do contexto cultural foi registrada em diários de campo elaborados pelos entrevistadores.

Se, por um lado, as cotas de sexo ou segmento social reproduzem razoavelmente a realidade sócio-demográfica dos jovens brasileiros, por outro, o mesmo não ocorre com o critério adotado para a parentalidade (termo que engloba maternidade e paternidade). A escolha superdimensionada atendeu ao propósito de obter informações mais precisas sobre o universo de jovens que iniciaram a carreira reprodutiva na adolescência. Neste sentido, a cota da etapa qualitativa utilizada foi de $60 \%$ do total de depoimentos, quando, no grupo etário considerado, na população juvenil geral, cerca de $30 \%$ das mulheres e menos de $25 \%$ dos homens têm filhos 24,32. Esta decisão produz um perfil específico dos homens entrevistados: são rapazes mais precoces sexualmente e com um número maior de parceiras, em relação à população masculina juvenil em geral.

\section{Entrevista: a narrativa biográfica retrospectiva}

A abordagem do tema assegurou bastante atenção ao relato das circunstâncias envolvidas na gravidez e aborto. Um roteiro semi-estruturado permitiu a comparabilidade de depoimentos colhidos em diferentes cidades e por diferentes pesquisadores, contendo 12 módulos relacionados à trajetória de vida. No tema aqui em exame, foram investigados: a idade do parceiro(a); o processo de tomada de decisões; se o parceiro tomou conhecimento da gravidez e do aborto e qual sua reação; os tipos de apoio recebido; a participação das famílias na escolha de manutenção (ou não) da gestação; as circunstâncias e o método empregado; se foi realizado somente um aborto; quais as concepções sobre o aborto e as opiniões sobre a gravidez. Solicitou-se na entrevista uma descrição detalhada da sucessão dos acontecimentos, desde a constatação da gestação até as negociações/escolhas em prol de sua continuidade ou interrupção. Não somente foram investiga- 
das as experiências de aborto, mas também as cogitações em torno dessa prática, as tentativas, o contexto relacional e a rede social na qual as alternativas foram consideradas. Respostas explícitas sobre a possibilidade de um aborto permitiram detalhar o desenrolar dos eventos, a partir da descoberta da gravidez. $\mathrm{O}$ fato dos entrevistados terem sido claramente indagados sobre a idéia do aborto possibilitou a obtenção de histórias com tentativas (bem-sucedidas ou não), desistências ou até ausência de referência e intenção a essa possibilidade.

Os entrevistadores da etapa qualitativa, em número de 32, eram, em sua grande maioria, estudantes de pós-graduação em ciências sociais, com experiência anterior em pesquisa qualitativa, treinados previamente para a temática e com o emprego de consentimento informado. Foi assegurada a confidencialidade das declarações. O trabalho de campo foi supervisionado pelas coordenadoras regionais da pesquisa. Cada entrevistador elaborou um relatório de campo, no qual retratou o contexto social e as condições da tomada do depoimento e as possíveis implicações envolvidas na declaração de um aborto, os motivos de eventuais omissões e as dificuldades de certificação de aborto espontâneo ou induzido. As entrevistas tiveram duração média de uma hora e meia, sendo integralmente gravadas e transcritas pelos entrevistadores. A equipe de pesquisa apresentou um predomínio de mulheres embora dez homens tenham participado. A primeira autora deste artigo entrevistou alguns jovens pertencentes a distintas inserções sociais 30 .

\section{Categorização do aborto: o viés da declaração e as evidências empíricas}

O aborto foi pesquisado em relação às atitudes de princípio e às atitudes de princípio em situação e as práticas efetivas dos jovens confrontados com o problema da gravidez. Esta estratégia permitiu apresentar as circunstâncias reprodutivas nas quais a gravidez e o aborto ocorrem, o posicionamento dos jovens e o processo de negociação envolvido numa decisão reprodutiva na adolescência. O fato do jovem ter sido convidado a revisitar o passado recente de sua trajetória permitiu que ele falasse do modo como as questões sobre o aborto foram tratadas, bem como saber dos fatores envolvidos na decisão. Classificamos um aborto como "certamente induzido" quando há, em algum trecho da narrativa, "menção explícita” à sua indução, com indicação do uso de algum método, remédio ou correlato para viabilizá-lo. A menção à procura por um serviço de saúde, clí- nica, médico ou farmacêutico também constitui um indicativo dessa categoria. O aborto é considerado "possivelmente induzido" quando há "menção implícita" a alguns dos meios, ou quando há, no conjunto da entrevista, algum trecho que indique que "é mais ou menos provável que a indução ou tentativa tenha ocorrido". Por fim, entende-se por "aborto possivelmente espontâneo" aquele em que não há alusão ao uso de qualquer método para interrupção da gravidez, mas afirma-se a existência de um aborto.

Os exemplos a seguir mostram como se procedeu à classificação dos tipos de aborto. Uma jovem pertencente à camada popular atribuiu ao aborto "espontâneo", aos quatro meses de gestação, susto e contrariedades. Revelou ainda uso oral e local do Misoprostol 33 (nome comercial Cytotec), adquirido na farmácia, por "indicação médica". Em relação à gravidez que resultou em um aborto "espontâneo" ela diz: "perdi de quatro meses, foi de um susto que eu tomei, eu tava com raiva, ele tava me enchendo o saco (...). A gente veio de uma festa, e eu já tava enraivada mesmo com ele. Ele tava me enchendo. Quando a gente chegou aqui, na frente de casa, eu e ele ficamos namorando (...) quando eu fui reparar, vinha duas pessoas de lá (...). Aí eu corri, fiquei com aquela pressão (...). Aí fui dormir e, quando foi três horas da manhã, me senti mal (...) Desceu" (Jovem de 19 anos, mãe, Salvador, segmento popular - Entrevista A).

Em relação ao uso "ineficaz" do Misoprostol, explica: "eu fiz a ultra-sonografia (...). Na maternidade, a médica mandou tomar três Cytotec, e eu tomei e não perdi! Graças a Deus minha filha está bem saudável. Mãinha foi na rua comigo e com meu marido, compramos (...) e eu tomei esses três, coloquei, aliás, os três, mas de duas em duas horas. Desceu um tanto de sangue" (Jovem de 19 anos, mãe, segmento popular, Salvador, Entrevista A).

O caso desta entrevistada, cuja primeira gestação é objeto de análise, dá lugar à hipótese de um aborto "possivelmente induzido". Através de evidências empíricas de outros estudos 19,33, e da própria experiência de campo de uma das autoras com mulheres internadas em enfermarias por abortamento, gradualmente relaciona-se a referência genuína ao susto, à raiva, situações de conflito com os parceiros a tentativas mal sucedidas de aborto. Por outro lado, também se sabe que esses motivos podem ser suficientes para provocar um aborto espontâneo 33. Optamos pela classificação como uma "possível" indução na primeira gestação porque a menção ao "susto", o domínio do uso de Misoprostol e a posição favorável ao 
aborto por todos os envolvidos indicaram a possibilidade de um aborto induzido. Um outro elemento são as referências em estudos nos quais o uso de medicamentos como o Misoprostol é interpretado como integrado pelas mulheres 33,34 .

\section{A tipologia de experiências de aborto}

O panorama extraído das circunstâncias reprodutivas e sexuais permitiu a criação de uma tipologia de experiências de aborto, em uma classificação que propõe, em um contínuo, a cogitação do aborto, a tentativa de concretização, sua realização e a exclusão da possibilidade de interromper a gestação 30 . A hipótese de realizar um aborto e a concretização efetiva da interrupção da gravidez se contrapõem a uma visão positivista sobre as atitudes frente ao aborto (ter feito $v s$. não ter feito). Nosso argumento é de que somente uma minoria de jovens nunca cogitou a idéia de interrupção da gravidez.

Na elaboração da tipologia foi necessária a menção do jovem sobre algum método ou local em que realizou o aborto (ou para uma tentativa fracassada), ou de respostas que sinalizam a não problematização da gravidez, como: "em nenhum momento pensamos nisso, nem eu nem ele (a)"; "sou contra o aborto e ele(a) também"; "foi bem desejado e de certa forma até planejado"; "não, depois que ele soube ele queria muito ser pai"; "eu queria ser mãe"; "não, não concordou" ou, finalmente, "aceitei com o maior carinho e ajudei ela”. A categoria "pensou no aborto" é reveladora da posição e participação do parceiro ou da família na decisão dos jovens que aventam a hipótese do aborto, mas dele desistem. Já para incluir um rapaz na categorização de "jovem com experiência de aborto", é preciso que ele tenha aludido a certas circunstâncias tais como: à certeza ou à dúvida sobre a concretização do aborto, ao fato do procedimento ter sido claramente expresso pela parceira, ou mencionado de forma indireta por terceiros. Na grade classificatória foram construídas quatro categorias, sendo selecionada apenas a primeira gestação e seu desfecho, ainda que um entrevistado tenha relatado mais de um episódio. A seleção de apenas uma gestação objetiva a identificação, em ordem de importância, de quem $\mathrm{fez}$ aborto, tentou fazêlo e pensou nessa hipótese. Um grande número de tentativas fracassadas por abortamento é apontado na literatura sobre o tema como um problema enfrentado por mulheres, face a uma gravidez não prevista 17,19. No entanto, poucos estudos analisam mais profundamente essa problemática.

\section{Resultados}

Tipos de experiências de aborto e diferenças de gênero

Em 86 entrevistas é expressivo o número de homens que declarou aborto realizado por parceiras (43\%), especialmente quando comparado à proporção declarada pelas mulheres (17\%) (Tabela 1). Aquino et al. 31 encontraram também um maior percentual de homens entrevistados que relataram um aborto provocado $(41,3 \%$ de relatos de rapazes contra $15,3 \%$ de informação das jovens). A grande proporção de relatos masculinos sobre o aborto não se repete em relação às demais experiências (tentar, pensar e não pensar no aborto). Entretanto, $73 \%$ dos jovens entrevistados, no universo pesquisado, "pensou, tentou ou realizou aborto", o que evidencia uma proporção expressiva da hipótese de aborto e uma tendência à aceitação "imanente da prática” 35 . Assim, a possibilidade de interrupção da gravidez, ainda que na clandestinidade, supera o dualismo fez ou não o aborto. Os dados assim classificados evidenciam um espectro decisório mais amplo, como "um horizonte possível diante de uma gravidez”. As escolhas diante desse evento são construídas pelas condições sociais, visão de mundo e biografia individual de cada jovem, bem como pelo gênero 35,36.

\section{Efeitos de declaração}

O predomínio de experiências masculinas de aborto pode ser considerado como efeito de declaração: os rapazes possivelmente relatam com maior facilidade uma gravidez e um aborto que eles, muitas vezes, não possuem certeza

Tabela 1

Proporção de jovens de 18 a 24 anos de Porto Alegre, Rio de Janeiro e Salvador, Brasil, de ambos os sexos, com experiência de gravidez em relação ao tipo de experiência de aborto.

\begin{tabular}{|c|c|c|c|c|c|c|}
\hline \multirow{2}{*}{$\begin{array}{l}\text { Tipo de experiência } \\
\text { de aborto }\end{array}$} & \multicolumn{2}{|c|}{ Feminino } & \multicolumn{2}{|c|}{ Masculino } & \multicolumn{2}{|c|}{ Total } \\
\hline & $\mathrm{n}$ & $\%$ & $\mathrm{n}$ & $\%$ & $\mathrm{n}$ & $\%$ \\
\hline Aborto & 7 & 17 & 20 & 43 & 27 & 31 \\
\hline Tentativa & 8 & 20 & 5 & 11 & 13 & 15 \\
\hline Pensou & 13 & 33 & 10 & 22 & 23 & 27 \\
\hline Não pensou & 12 & 30 & 11 & 24 & 23 & 27 \\
\hline Total & 40 & 100 & 46 & 100 & 86 & 100 \\
\hline
\end{tabular}

$\mathrm{n}=86$ jovens.

Fonte: Pesquisa GRAVAD, 2000 (entrevistas qualitativas) 32. 
e nos quais não se sentem necessariamente implicados ou responsáveis. Muitos jovens não sabem ao certo se a gravidez ocorreu ou ainda a quem cabia a paternidade. As mulheres são assertivas ao declarar a concretização de um aborto, o que pode ser compreendido pelo processo vivido por elas até a tomada de uma decisão.

\section{Iniciação amorosa e sexual}

Como dito anteriormente, os homens declaram mais histórias de aborto, o que pode ser interpretado como número maior de parceiras eventuais no início de sua vida sexual. Os rapazes tendem a ter um maior número de parceiras sexuais e, assim, estão potencialmente expostos a um maior número de situações de engravidamento de parceiras, sobretudo se considerarmos a baixa incorporação pelos homens dos cuidados contraceptivos 12 .

Há diferenças marcantes na iniciação sexual de rapazes e moças: enquanto a trajetória feminina, de modo geral, é marcada por relações afetivas duráveis; o modelo masculino é caracterizado por relacionamentos com forte ênfase na sexualidade sem o compromisso do vínculo afetivo. Nos primeiros anos de vida sexual as moças desenvolvem uma maior experiência relacional comparativamente aos rapazes, que vivenciaram experiências sexuais pontuais. A iniciação sexual das mulheres entrevistadas assinala uma construção tradicional da sexualidade feminina, na qual as representações de feminilidade, acerca da importância da fertilidade, monogamia - ainda que o parceiro mantenha relações com outras moças 35,37 .

\section{Métodos de abortamento empregados}

As entrevistas evidenciam diferenças relativas aos métodos utilizados em tentativas e na realização do aborto na primeira gestação. Notase ausência de menção a métodos perfurantes, como sondas ou correlatos e a maioria dos rapazes declararam não possuir conhecimento do método usado pelas parceiras. O Misoprostol, outros "remédios" e a clínica são os métodos referidos preferidos pelos jovens de ambos os sexos, equivalendo a grande parte do total de procedimentos abortivos (Tabela 2). Vale observar que a menção a um método não exclui o recurso a qualquer outro: combinações de chás com remédios, injeções com Misoprostol, chás e injeções são relatados nas entrevistas. O predomínio de chás como recurso referido nas tentativas é indicativo de uma estratégia de testagem de uma possível gravidez e da tentativa de "fazer descer as regras", sem nomeação desse recurso como tentativa de aborto 12,20 .

\section{Decisão de abortar}

O modo como os jovens narram as conversas em torno da gravidez não prevista - nas quais a cogitação do aborto tem lugar assegurado - assinala sua aceitabilidade nos diálogos entre parceiros, pares e família. Desse modo, ele não é alvo de interdição total; é aventado entre e por familiares dos jovens, aparecendo também nos relatos sobre as experiências de amigos e terceiros. Os interlocutores são parte importante do contexto decisório: a decisão é raramente tomada pelos jovens de forma solitária, principalmente porque as famílias se posicionam, são importantes fontes de consulta, oferecem condições materiais e apoio no caso do aborto. Entre os entrevistados, $62 \%$ das moças e $45 \%$ dos rapazes compartilharam a notícia da gravidez com pares e familiares. Em especial, as mães são coadjuvantes consideradas pelos jovens fundamentais no enfrentamento da decisão (dados não apresentados). Veja-se o caso da mãe de uma jovem, oriunda de camadas populares e residente em Salvador, que declara um aborto "espontâneo" na primeira gestação e relata que em três ocasiões de engravidamento a mãe "sugere" à filha a fazer o aborto como alternativa. No caso da primeira gestação a moça acata a opinião da mãe. Contudo, pouco tempo depois volta a engravidar e se recusa terminantemente - a abortar uma segunda vez, a despeito da "pressão" materna: “depois veio a minha família toda de novo, dizendo que era pra não deixar pagar, aí me perguntaram se eu queria tirar e falei que não, que dessa vez eu não tiro nem se me amarrarem e me levarem para tirar, eu não quero tirar. Aí perguntaram a ele se ele queria deixar, ele disse que não ia deixar tirar porque agora a responsabilidade era dele. Aí minha mãe deixou" (Jovem de 19 anos, mãe, segmento popular, Salvador - Entrevista B).

O depoimento ilustra os dilemas presentes na negociação familiar. Vilar \& Gaspar 15 observaram em pesquisa semelhante, realizada em Portugal, que muitas mães de adolescentes não conseguem impedir que a gravidez prossiga $\mathrm{e}$ salientam as reações de tolerância e resignação, por parte delas. Segundo os autores, aceitar a parentalidade dos filhos é, em parte, expressão de constrangimentos - sobretudo em famílias de segmentos populares - pelo fato de, também, essas mulheres terem se tornado mães na adolescência, ou de outros membros da parentela terem passado por circunstância 
Tipo de experiência de aborto de jovens de 18 a 24 anos, de ambos os sexos, de Porto Alegre,

Rio de Janeiro e Salvador, Brasil, em relação aos métodos mencionados para tentar e realizar o aborto.

\begin{tabular}{|c|c|c|c|c|c|c|}
\hline \multirow[t]{2}{*}{ Experiências de aborto } & \multicolumn{6}{|c|}{ Métodos mencionados } \\
\hline & Clínica & $\begin{array}{l}\text { Misoprostol } \\
\text { e/ou remédio }\end{array}$ & $\begin{array}{c}\text { Chás } \\
\text { caseiros }\end{array}$ & Injeção & Não sabe & Total \\
\hline \multicolumn{7}{|l|}{ Feminino } \\
\hline \multicolumn{7}{|c|}{ Tipo de experiência de aborto } \\
\hline Aborto & 3 & 3 & 0 & 0 & 0 & 7 \\
\hline Tentativa & 0 & 3 & 6 & 1 & 0 & 10 \\
\hline Total & 3 & 6 & 6 & 1 & 1 & 17 \\
\hline \multicolumn{7}{|l|}{ Masculino } \\
\hline \multicolumn{7}{|c|}{ Tipo de experiência de aborto } \\
\hline Aborto & 3 & 2 & 2 & 1 & 12 & 20 \\
\hline Tentativa & 1 & 2 & 2 & 1 & 0 & 6 \\
\hline Total & 4 & 4 & 4 & 2 & 12 & 26 \\
\hline
\end{tabular}

$\mathrm{n}=40$, jovens com experiências e tentativa de aborto.

Fonte: Pesquisa GRAVAD, 2000 (entrevistas qualitativas) 32.

semelhante, o que as impede de impor "sanções” morais aos filhos, frente à não observância do ideal cada vez mais difundido de uma idade adequada e mais tardia para a reprodução. Observamos nessa direção nos relatos que os rapazes e seus familiares geralmente indagam se a adolescente deseja interromper a gestação. Nessas circunstâncias a moça pode persistir em sua decisão de abortar, sem que o parceiro e a família apóiem integralmente tal escolha. No trecho a seguir, observa-se a intervenção e influência da mãe numa negociação favorável ao aborto na primeira gestação: "ela já teve uma gravidez antes dessa, mas abortou, uns oito meses antes. Ah, no momento a gente não tinha nenhuma preparação psicológica pra ser pai, era garotão. A gente veio amadurecer bastante depois do aborto. A família dela condenou na hora e a gente nem pôde impor resistência. Quem levou até o aborto foi justamente a mãe dela. A mãe dela foi logo levando ela pro médico. A mãe dela pagou setecentos reais" (Jovem, segmento médio, Salvador - Entrevista C).

Há também casos nos quais o rapaz sabe da tentativa, mas evita envolver-se, por não reconhecer a paternidade. Destacamos uma situação na qual a ex-parceira tomou remédio - Misoprostol e ele atribui o óbito ao uso dessa medicação, sugerindo desconhecimento do rapaz sobre a causa de morte e o fato de qualquer negociação incluir a possibilidade de tensões entre os atores sociais envolvidos, face aos riscos associados ao aborto ilegal: “...aí tudo constava que era meu, sendo que a mãe dela não sabia que ela estava grávida. Mas (...) os amigos dela, todos sabiam. Ela começou a tomar remédio, não desceu a criança, ai morreu, ela não resistiu. De tanto tomar remédio ficou doente e não conseguiu. Morreu no parto, a criança sobreviveu. Tentei depois conversar com a avó dela pra falar se eu podia fazer um exame para saber se o filho era meu. Não consegui conversar" (Jovem de 19 anos, sem paternidade, segmento popular, Rio de Janeiro, Entrevista D).

Nas entrevistas com rapazes, muitas vezes o conhecimento da gravidez da parceira é admitido provisoriamente, já que a gestação não é suficientemente constatada, há incerteza se, de fato, a gravidez da parceira ocorreu, se houve aborto ou ainda há dúvidas sobre a paternidade. Esse fato certamente amplia a complexidade de categorização dos casos e tentativas de aborto, na medida em que os homens se referem a situações sobre as quais as informações são incertas, sobretudo quando estão afastadas das parceiras à época da descoberta da gravidez. O aborto mencionado pelos rapazes, mesmo quando eles têm duvidas, é considerado, pois partimos do pressuposto de que se a declaração de um aborto é feita, é porque ele é admitido na trajetória como tal.

\section{Considerações finais}

Face a uma gravidez não prevista na adolescência, constata-se a expressiva presença de cogitação do aborto entre os entrevistados. As 
condições sociais impostas pelo enquadramento legal do aborto interferem fortemente na tomada de decisões durante a gravidez. De acordo com nossa pesquisa, os extremos integram um continum relativo ao comportamento dos jovens: a cogitação do aborto se apresenta na maior parte das experiências relatadas, o que significa que os jovens não aceitam simplesmente uma gestação com naturalidade, como uma inescapável imposição de maternidade ou paternidade mas, sim, que há uma expressiva tendência à aceitação da hipótese do aborto 35 , apesar da dificuldade de realizá-lo. Nesse sentido, os dados ajudam a problematizar o discurso hegemônico sobre o crescimento da gravidez na adolescência no país, discurso este que dissolve a distinção entre gravidez e parentalidade na adolescência. É verdade que apenas uma pequena parcela de jovens possui condições de viabilizar a tempo a opção de abortar. Os jovens e suas famílias sabem que a gravidez pode ocorrer e que o aborto é uma alternativa, ainda que em contexto de ilegalidade.

Nos resultados conhecidos há uma possibilidade de subestimação, em virtude dos limites do universo pesquisado, do silêncio das mulheres sobre suas experiências, de seu desconhecimento sobre o que de fato ocorreu. A não declaração dos abortos pelas moças não é devida somente à ilegalidade, mas também aos valores que definem a identidade em termos da reprodução e maternidade 11,15,36,38 e das representações negativas associadas ao aborto. Por outro lado, é inegável a contribuição dos relatos masculinos nos resultados da investigação e cabe ressaltar a relevância da incorporação dos homens em pesquisas relativas à reprodução.
Suas narrativas elucidam, em parte, as omissões presentes em pesquisas sobre o aborto, além de favorecer a contextualização das negociações relativas às decisões reprodutivas.

A sistematização das experiências dos jovens indicou que o aborto como um horizonte de possibilidade é uma dimensão da reprodução freqüente na iniciação sexual, contribuindo para uma compreensão mais ampla da gravidez na adolescência e das transformações dos valores vinculados à sexualidade e à reprodução. Em síntese, a possibilidade de realizar um aborto integra o quadro gerado por uma gravidez não prevista. Entretanto é preciso considerar as barreiras que são enfrentadas para regular a reprodução, especialmente num contexto como o do Brasil no qual o aborto é ilegal e onde permanece insuficiente o acesso à contracepção e aos serviços de saúde. Junte-se a isto a radical heterogeneidade de oportunidades sociais, de escolarização, inserção profissional e a persistência da assimetria de gênero, que contribuem para certas decisões tomadas pelos jovens na passagem para a vida adulta.

O fato da proporção de gravidez na adolescência se manter elevada no país, mesmo com a tendência de queda verificada nos anos 2000, não significa que os jovens não ambicionem controlar sua reprodução e garantir a autodeterminação e o exercício dos seus direitos sexuais e reprodutivos. Entretanto, enquanto algumas jovens com recursos são atendidas para realizar o aborto de modo seguro, adolescentes em condição de vulnerabilidade social são obrigadas a se confrontar com os riscos físicos e o constrangimento moral do aborto clandestino e inseguro.

\section{Resumo}

Este artigo objetiva desvelar a presença da idéia do aborto como elemento do âmbito das reflexões dos jovens sobre uma gravidez na adolescência. Analisam-se dados de entrevistas semi-estruturadas com 123 jovens de 18 a 24 anos de ambos os sexos, moradores de Porto Alegre, Rio de Janeiro e Salvador, Brasil, pertencentes a distintos estratos sociais. A partir de informações sobre as circunstâncias amorosas, sexuais e reprodutivas dos entrevistados, foi construída uma tipologia das experiências de aborto, em um gradiente que vai desde a cogitação, a tentativa de concretizá-lo, sua realização e até a exclusão da possibilidade de interrupção da gestação. Os dados apontam que $73 \%$ dos jovens con-

siderou a possibilidade do aborto, demonstrando uma expressiva presença da idéia desse recurso face à gravidez não prevista, mesmo em contexto de ilegalidade. Entre os 86 jovens com experiência de gestação, 27 declararam a prática do aborto, sendo vinte rapazes e sete moças. Os resultados indicam diferenças relativas ao gênero e contribuem para a compreensão da gravidez na adolescência ao examinar o aborto induzido, dimensão encoberta no debate público e científico sobre o tema.

Aborto Induzido; Gravidez na Adolescência; Sexualidade 


\section{Colaboradores}

S. O. Peres e M. L. Heilborn redigiram o artigo. S. O. Peres é responsável pela sistematização, categorização e análise do material empírico. M. L. Heilborn é responsável pela edição do texto.

\section{Agradecimentos}

A investigação Gravidez na Adolescência: Estudo Multicêntrico sobre Jovens, Sexualidade e Reprodução no Brasil (Pesquisa GRAVAD) foi elaborada por Maria Luiza Heilborn (Instituto de Medicina Social, Universidade do Estado do Rio de Janeiro - IMS/UERJ), Michel Bozon (Institute National d'Études Démographiques - INED, França), Estela M. L. Aquino (Programa Integrado de Pesquisa e Cooperação Técnica em Gênero e Saúde/Universidade Federal da Bahia MUSA/UFBA) e Daniela Knauth (Núcleo de Antropologia do Corpo e Saúde/Universidade Federal do Rio Grande do Sul - NUPACS/UFRGS). O estudo foi realizado por três centros: Programa em Gênero, Sexualidade e Saúde (IMS/UERJ), MUSA/UFBA e NUPACS/ UFRGS. Os principais resultados do inquérito encontram-se publicados no livro O Aprendizado da Sexualidade: Reprodução e Trajetórias Sociais de Jovens Brasileiros (Rio de Janeiro: Garamond; 2006), onde podem ser obtidas informações sobre a composição detalhada da equipe de pesquisadores. Agradecemos também à Fundação Ford, ao programa de bolsas do Conselho Nacional de Desenvolvimento Científico e Tecnológico e à Coordenação de Aperfeiçoamento de Pessoal de Nível Superior.

8. Cunha A, Monteiro D. Gravidez na adolescência como problema de saúde pública. In: Monteiro D, Cunha A, Bastos A, organizadores. Gravidez na adolescência. Rio de Janeiro: Revinter; 1998. p. 32-42.

9. Dadoorian D. Pronta para voar: um novo olhar sobre a gravidez na adolescência. Rio de Janeiro: Editora Rocco; 2000.

10. Katz RA. Adolescentes e maternidade: um destino, um problema, uma escolha? [Dissertação de Mestrado]. Rio de Janeiro: Instituto Fernandes Figueira, Fundação Oswaldo Cruz; 1999.

11. Le Van C. Les grossesses à l'adolescence. Normes sociales, réalisés vécues. Paris: Éditions L’Harmattan; 1998.

12. Leal OF, Legoy B. Pessoa, aborto e contracepção. In: Leal OF, organizador. Corpo e significado: ensaios de antropologia social. Porto Alegre: Universidade Federal do Rio Grande do Sul; 1995. p. 55-75.

13. Monteiro M. Gravidez na adolescência no Estado do Rio de Janeiro (Brasil). Investigación en Salud 1998; 1:57-63.

14. Paiva AS, Caldas MLC, Cunha AA. Perfil psicossocial da gravidez na adolescência. In: Monteiro D, Cunha A, Bastos A, organizadores. Gravidez na adolescência. Rio de Janeiro: Revinter; 1998. p. 7-30.

15. Vilar D, Gaspar AM. Traços redondos. A gravidez em mães adolescentes In: Pais JM, organizador. 
Traços e riscos de vida: uma abordagem qualitativa dos modos de vida juvenis. Porto: Ambar; 1999.

16. Campbell N, Franco K, Jurs S. Abortion in adolescence. Adolescence 1998; 92:813-23.

17. Crespin J. Gravidez e abortamento na adolescência: novos dados, velhos desafios. Rev Paul Pediatr 1998; 16:197-200.

18. Duarte G. Contracepção e aborto: perspectiva masculina [Dissertação de Mestrado]. São Paulo: Departamento Materno-Infantil, Universidade de São Paulo; 2000.

19. Costa SH. Aborto provocado: a dimensão do problema e a transformação da prática. In: Giffin K, Costa SH, organizadores. Questões de saúde reprodutiva. Rio de Janeiro: Editora Fiocruz; 1999. p. 163-84.

20. Osis, MJD. Dificuldades para obter informações da população de mulheres sobre o aborto ilegal. Rev Saúde Pública 1996; 30:444-51.

21. The Alan Guttmacher Institute. Aborto clandestino: uma realidade latino americana. New York: The Alan Guttmacher Institute; 1994.

22. Ávila MB. Direitos sexuais e reprodutivos: desafios para as políticas de saúde. Cad Saúde Pública 2003; 19 Suppl 2:S465-9.

23. Bajos N, Ferrand M, editors. De la contracepcion à l'avortement:sociologie dês grossesses non prévus. Paris: Institut National de la Santé et de la Recherche Médicale; 2002.

24. Sociedade Civil Bem-Estar Familiar no Brasil. Pesquisa Nacional sobre Demografia e Saúde 1996. Rio de Janeiro: Sociedade Civil Bem-Estar Familiar no Brasil; 1997.

25. Di Giovanni R. Projetos de vida: um estudo das representações femininas do aborto [Dissertação de Mestrado]. Campinas: Departamento de Antropologia Social, Universidade de Campinas; 1983.

26. Ramirez-Galvez M. Os impasses do corpo: ausências e preeminências de homens e mulheres no caso do aborto voluntário [Dissertação de Mestrado]. Campinas: Departamento de Antropologia Social, Universidade de Campinas; 1999.

27. World Health Organization. Sexual relations among young people in developing countries evidence from WHO case studies. Geneva: World Health Organization; 2001.
28. Blay E. Projeto de lei sobre o aborto. Estudos Feministas 1993; 1:430-4.

29. Ehrenfeld N. Female adolescents at crossroads: sexuality, contraception and abortion in Mexico. In: Mundingo A, Indriso C, editors. Abortion in the developing world. Part III: Adolescent sexuality and abortion. New Delhi: World Health Organization; 1999. p. 368-86.

30. Peres SO. Aborto e juventude: um horizonte de possibilidades diante da gravidez na adolescência [Tese de Doutorado]. Rio de Janeiro: Instituto de Medicina Social, Universidade do Estado do Rio de Janeiro; 2003.

31. Aquino EML, Heilborn ML, Knauth D, Bozon M, Almeida MC, Araújo J, et al. Adolescência e reprodução no Brasil: a heterogeneidade dos perfis sociais. Cad Saúde Pública 2003; 19 Suppl 2: S377-88.

32. Heilborn ML, Aquino EML, Bozon M, Knauth DR. Aproximações sócio-antropológicas sobre a gravidez na adolescência. Horizontes Antropológi$\cos 2002 ; 17: 13-45$.

33. Mercucc VB, Bonfim JRA. Casos de desinformação farmacêutica: drogas EP de alta dosagem, acetado de medroxiprogesterona e misoprostol. In: Wolffers I, Hardon A, Jansen, organizadores. O marketing da fertilidade: menstruação aborto e indústria farmacêutica. São Paulo: Editora Hucitec; 1991. p. 113-28.

34. Barbosa MR, Arrilha M. A experiência brasileira com o Cytotec. Estudos Feministas 1993; 1:408-17.

35. Bourdieu P. Esboço de uma teoria da prática. In: Ortiz R, organizador. Sociologia. São Paulo: Editora Ática; 1983. p. 47-8. (Grandes Cientistas Sociais, 39).

36. Ferand M, Jaspard M. L'interruption voluntaire de la grossesse. Paris: PUF; 1987.

37. Bozon M. Sociologie de la sexualité. Paris: Nathan Université; 2002. (Sociologie, 128).

38. Bailey PE, Bruno ZV, Bezerra MF, Queirós I, Oliveira CM. Adolescent's decision-making and attitudes towards abortion in north-east Brazil. J Biosoc Sci 2003; 35:71-82.

Recebido em 28/Abr/2005

Versão final reapresentada em 18/Ago/2005 Aprovado em 24/Ago/2005 